\title{
Restoration of Distal Third Leg and Heel Soft Tissue Defects Using Local Muscle Flaps
}

\author{
OSAMA ALSHAHAT, M.D.; MAGDY ABD-AL MOKTADER, M.D.; MAHMOUD NASEF, M.D. and \\ MAHMOUD ABD EL-HAMID, M.Sc. \\ The Department of Plastic and Burn Surgery, Faculty of Medicine, Al-Azhar University, Cairo, Egypt
}

\begin{abstract}
Background: Wound coverage of exposed lower third tibia and ankle region remains a difficult task. Muscle flaps are preferred for infected wounds especially where there are exposed bone, joint and/or tendons.

Patients and Methods: This study includes 60 patients with soft tissue defects at the distal third of leg. The study duration was from April 2014 to April 2016. Cases in this study were classified into two groups. Flap selection was random. Group (A) include 30 patients reconstructed by distally based peroneus brevis muscle flap. Group (B) include 30 patients reconstructed by distally based medial hemisoleus muscle. Routine investigations included full laboratory investigations and plain X-rays. Patients were operated under regional or general anesthesia. Flap was assessed daily and first dressing was done on day five of surgery. Patients were discharged once flap and split skin grafting were healthy on assessment after first dressing and subsequent dressings. Patients were followed up twice weekly for the first month and then once a month for six months.
\end{abstract}

Results: Group (A): Mean age 41 year, 29 cases male and one case female. Site of the soft tissue defect: 14 case at the lateral malleolus, 2 cases at the medial malleolus, 9 cases for exposed tendoachillies, 4 cases at the anterior part of the ankle joint and one case at the peritibial part of the distal third leg. Size of the defect width rang from $3 \mathrm{~cm}$ to $10 \mathrm{~cm}$ and length rang from $3 \mathrm{~cm}$ to $12 \mathrm{~cm}$. Splitting of the muscle was done for 7 patients to increase its width and 23 case non splitting. Complications: Only flap necrosis in one case need other procedure for reconstruction and complete successful in 29 case. Group (B): Mean age 41 year, 28 case male and 2 cases female. Site of the defect: 16 case at the medial malleolus and 14 cases at the peritibial part of distal third leg. Size of the defect width rang from $3 \mathrm{~cm}$ to $7 \mathrm{~cm}$ and length from $3 \mathrm{~cm}$ to $10 \mathrm{~cm}$. Complication: Flap failure occurred in 11 case and complete successful in 19 cases.

Conclusion: Local muscle flaps is areliable method for reconstruction of soft tissue defects at the distal third of the leg.

Key Words: Distal third leg - Peronus brevis - Hemisoleus - Muscle flap.

\section{INTRODUCTION}

Muscle flaps have demonstrated, both clinically and experimentally, a series of advantages over local skin flaps and fasciocutaneous flaps for the management of complex wounds. The malleability of muscle allows it to effectively obliterate dead space while the dense capillary network facilitates antibiotic deposition. Additionally, muscle flaps are more effective than their counterparts in overcoming varying degrees of bacterial colonization and infection [1]. Muscle flaps have demonstrated a rapid, early augmentation of blood flow in response to an inoculum, providing greater degrees of bacterial growth inhibition and bacterial elimination than random skin flaps or fasciocutaneous flaps. Muscle flaps also have demonstrated more rapid collagen deposition and greater tissue ingrowth. These advantageous characteristics likely account for their high level of success when used to manage hostile wounds [2].

\section{Surgical anatomy:}

\section{Peroneus brevis flap anatomy:}

The peroneus brevis muscle is located deep to the peroneus longus in the lateral compartment of the leg. The extensor digitorum longus is found anterior to the peroneus brevis in the anterior compartment, and the flexor halluces longus is posterior to it in the deep posterior compartment. The peroneus brevis muscle originates from the mid shaft of the lateral fibula, passing posterior to the lateral malleolus and inserting at the tuberosity of the fifth metatarsal bone. It remains muscular distal to the lateral malleolus, beyond which it is entirely tendinous. Motor supply to the peroneus muscles is from the superficial peroneal nerve, which is located superficially in the lateral compartment [3]. Originally, the peroneus brevis was 
a type II muscle flap, but it was reclassified by Mathes and Naha [4]. As type IV with a dominant pedicle or pedicles from the peroneal artery, located proximally, entering the muscle from its deep surface, and distal minor pedicles from the peroneal or anterior tibial vessels. When the flap is based distally, it is recommended that 3 fingerbreadths be left intact from the distal tip of the lateral malleolus [5].

On the basis of these surgical anatomies, this muscle is circumpennate, with an internal axial blood supply from 2 arteries corresponding to nearly its total length, and the blood supply enters through its deep surface. The muscle splitting through its superficial surface described for the coverage of larger defects [6].

\section{Hemisoleus muscle flap anatomy:}

The soleus muscle is a large, broad, and rather long muscle located at the posterior aspect of the leg. It is a bipenniform muscle consisting of a lateral and a medial head. The lateral head originates from the fibula head and body and the medial head originates from the medial side of the middle third of the tibia. The lateral and medial soleus muscles are separated in the midline by a septum, which is present in the distal part of the muscle. The two muscle heads join together to form the dorsolateral and dorsomedial component of the Achilles tendon. This tendon, which is formed by the soleus and gastrocnemius muscles, inserts on the calcaneum tuberosity [7].

The soleus muscle has a Type II blood supply according to the classification of Mathes and Nahai (1981). The medial hemisoleus flap is based on perforators arising from the posterior tibial artery and the flap can be either proximally or distally based. The presence of an adequate number of perforators and their uniform distribution along the medial half of the muscle ensures the survival of these flaps. The lowermost perforator was on average $6.5 \mathrm{~cm}$ from the tip of the medial malleolus and the second lowest perforator was $11.6 \mathrm{~cm}$ from the medial malleolus.

Due to the vascular pattern of the soleus muscle the medial half of the muscle showed consistent distribution of the perforators, whereas the lower lateral part of the muscle did not show significant blood supply. The adequate number of branches and their uniform distribution along the medial half of the muscle ensure survival of the medial hemisoleus flap. It is difficult to predict the reliability of the inferiorly based lateral hemisoleus flap because of the scarcity of the perforators in this region. Hence the clinical application of the inferiorly based lateral hemisoleus flap is limited to small lower lateral defects in selected cases [8].

\section{PATIENTS AND METHODS}

This prospective study was conducted in plastic and burn surgery department of alazhar university hospitals (Alhussien and Said Galal Hospitals). The study included 60 patients with soft tissue defects at the distal third of the leg. The study duration was from April 2014 to April 2016 Cases under the study were classified into two groups:

- Group (A): Included 30 patients with soft tissue defect at the distal third leg reconstructed by distally based peroneus brevis muscle flap.

- Group (B): Included 30 patients with soft tissue defect at the distal third leg and reconstructed by distally based hemisoleus muscle flap.

Flap selection was random. Data was collected including the patient's gender, age occupation, vascularity, and wound characteristics, including etiology, site and size.

Routine investigations included full laboratory investigations and plain X-rays. All patients underwent hand held Doppler evaluation of perforator to rule out atherosclerosis. Patients were operated under regional or general anesthesia. Postoperatively patients received antibiotics (ampicillin with sulbactam) for five days and adequate analgesia (Ketorolac tromethamine). First dressing was done on day five of surgery. Patients were discharged once flap and split skin grafting were survived on assessment after first dressing and subsequent dressings. Patients were followed-up twice weekly for the first month and then once a month for six months.

\section{Operative technique (Group A):}

After spinal anesthesia, patient is placed in supine or lateral position according to site of the defect and tourniquet is raised. Wound is debrided. Incision is taken $1-2 \mathrm{~cm}$ posterior to the fibular axis. Deep fascia is cut to expose peroneal compartment. Peroneus longus is visible. Peroneus longus is dissected off the underlying peroneus brevis muscle. The peroneus brevis muscle flap is raised from proximal to distal off its fibular attachment up to the constant distal perforator is identified or up to $6 \mathrm{~cm}$ from lateral malleolus. For defects over lower one third of the leg, when the defect at the distal third of the leg was large the proximal portion of the muscle belly was then split from the outer external surface, leaving the deep part of the muscle intact with its attached epimysium and 
periosteum the muscle was then turned over and gently sutured into the defect using fine $4 / 0 \mathrm{ab}-$ sorbable sutures. The split thickness skin graft was immediately applied, suction drainage was inserted, the donor site was closed, and the leg was dressed and secured using a posterior splint.

\section{Operative technique (Group B):}

Medial approach: The incision is drawn from the medial malleolus up to the proximal part of the leg located about $1.5 \mathrm{~cm}$ posterior to the medial aspect of the tibia. If the defect is in the leg, this line is usually continuous with the defect. A lazy $\mathrm{S}$-shaped incision can be performed for the harvest of this flap. After Incision of the skin and fascia In the middle third of the leg, the soleus muscle was dissected and separated from the gastrocnemius muscle posteriorly and the tibia and flexor digitorum anteriorly by blunt dissection. Secondary pedicles were identified in the distal portion of the muscle in order to provide a good arc of rotation. According to the anatomical consideration of medial hemisoleus muscle flap the distal perforator from the posterior tibial artery were present in the distal third of the muscle in most cases at least 2 constant perforators were present 5 to $7 \mathrm{~cm}$ above the medial malleolus. After confirmation of the presence of distal perforators the medial part of the muscle was subsequently divided longitudinally along the median raphe and downward, at the level of the distal perforators, from the lateral part of the muscle and separated from the Achilles tendon by sharp dissection. The major proximal pedicles were ligated and complete separation of the medial hemisoleus muscle flap were done down to the distal perforators. The distal dissection is stopped at the junction between the middle and distal thirds of the muscle. It is critical during this dissection to preserve the main pedicle supplying the distal muscle which presents about $7 \mathrm{~cm}$ proximal to medial malleolus ( 2 constant perforators). Meshed split thickness skin graft was taken from the thigh to cover the medial hemisoleus muscle flap. Suction drain was inserted. Donor site incision was closed. Dressing using antibiotic Vaseline gauze and bulky light dressing with fixation of ankle joint movement by planter splint from the foot up to knee.

\section{RESULTS}

This study included 60 patients having soft tissue defects at the distal third of the leg and heel. They were divided into 2 groups:

- $\operatorname{Group}(A)$ : Included 30 patients with soft tissue defect at the distal third leg for this group distally based peroneus brevis muscle flap technique was applied to cover the defect.
- Group (B): Included 30 patients with soft tissue defect at the distal third leg for this group distally based hemisoleus muscle flap technique was applied to cover the defect.

\section{Results of (Group A): (Table 1)}

The mean age in this group 41 year one case female $(3.3 \%)$ and 29 case were male $(96.7 \%)$. Site of injuries in this group showed that 14 case at lateral malleolus (46.2\%), 2 case at the medial malleolus (6.6\%), 9 case at calcenum with exposed tendoachilles $(29.7 \%), 4$ case at the anterior part of the ankle joint (13.2\%) and one case at the peritabial part of distal third of the leg $(3.3 \%)$. The size of soft tissue defects among this group showed that the minimum width size $(3 \mathrm{~cm})$ and maximum width size $(10 \mathrm{~cm})$ the mean size of the width in this group $(5 \mathrm{~cm})$. The minimum length size $(3 \mathrm{~cm})$ and maximum length size $(12 \mathrm{~cm})$ the mean length in this group $(6.5 \mathrm{~cm})$. The peroneus brevis muscle flap can cover small and medium size defect and for covering of large size defect splitting of the peroneus brevis was done which occurred in 7 cases in this group (23.3\%).

Complications distribution among this group showed that complications occurred in 6 cases among this group (20\%). Complete necrosis of the flap in one case (3.3\%) this case was presented by post traumatic exposed tendoachilles. Other procedure for coverage was done; partial loss of the graft in 4 cases (13.3\%), 2 cases from them was suffered from diabetes. This cases healed by frequent dressing and complete loss of the graft in one case $(3.3 \%)$, diabetic and hypertensive patient, regrafting was done. Post operative outcome among this group showed that complete successful in 29 cases of this group (96.7\%) with complete coverage of the defects.

\section{Results of (group B): Table (2)}

The mean age in this group 41 year. In this group 2 cases female $(6.7 \%)$ and 28 case were male $(93.3 \%)$. Site of injuries among this group showed that 16 cases at medial malleolus $(52.8 \%)$ and 14 cases at the peritabial part of distal third $\operatorname{leg}(47.2 \%)$.

The size of soft tissue defects among this group showed that the minimum width size $(3 \mathrm{~cm})$ andmaximum width size $(5 \mathrm{~cm})$ the mean width size of this group $(3.6 \mathrm{~cm})$. The minimum length size $(3 \mathrm{~cm})$ and maximum length size $(10 \mathrm{~cm})$ the mean length size $(5 \mathrm{~cm})$.

Complications among this group showed that complications occurred in 16 cases among this 
group $(52.8 \%)$. Complete necrosis of the flap in one case $(3.3 \%)$, this patient was male 58 years old, diabetic presented by post traumatic soft tissue defect at the right medial malleolus this case needed other procedure for coverage, distal necrosis of the flap occurred in 10 cases (33\%) 8 cases of them were presented by soft tissue defects over the medial malleolus and 2 cases at peritibial part of distal third leg, 2 cases from those patients were suffered from diabetes. This cases needed other
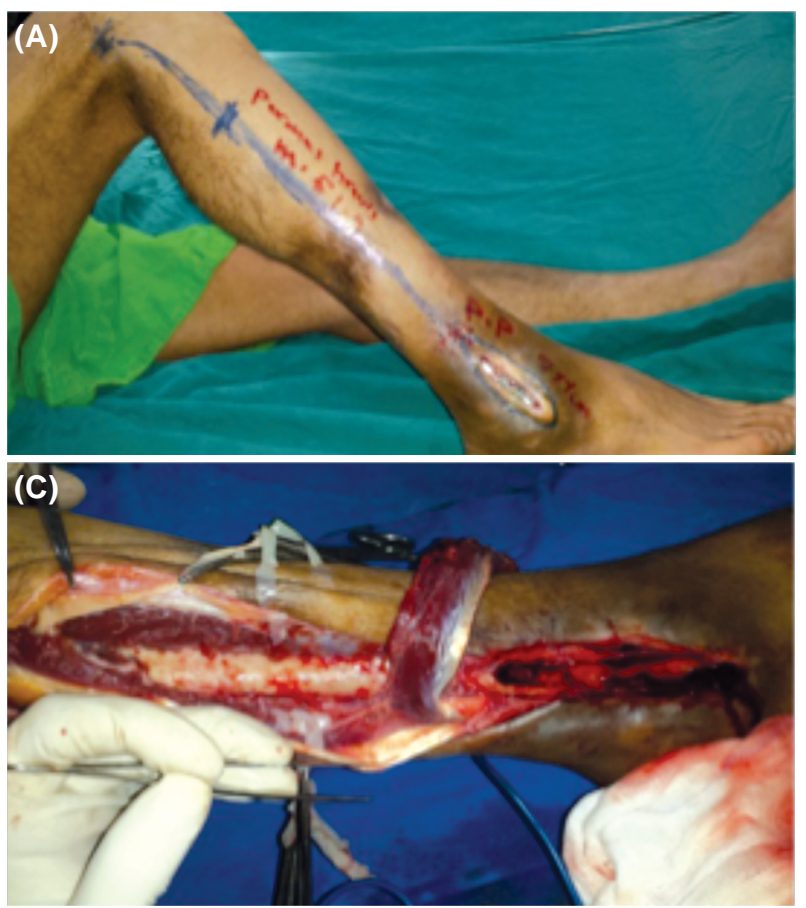

Fig. (1): Male patient 43 years old was presented by exposed plate over the lateral malleolus size of the defect $3 \times 6 \mathrm{~cm}$ (A) Marking of the flap, (B) After incision of skin and fascia and dissection of peroneus longus from peroneus brevis, (C) Complete elevation of the flap, (D) The flap covered by STSG.
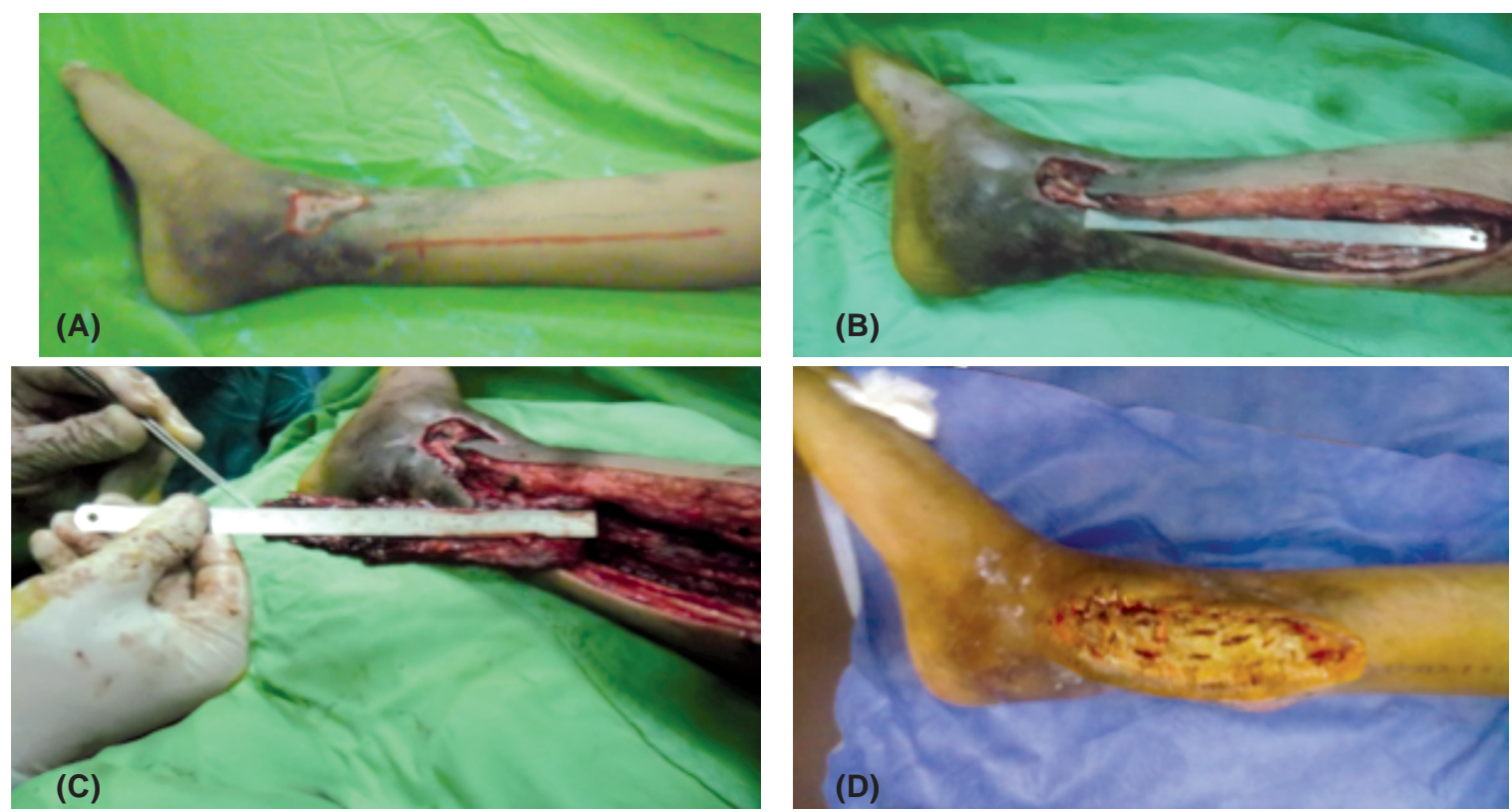

Fig. (2): Male patient 21 years old presented by post traumatic soft tissue defect at the medial malleolus $3 \times 3 \mathrm{~cm}$ (A) Flap marking, (B) Incision of skin and fascia, (C) Complete elevation of the flap, (D) Cover of the flap by STSG. procedure for coverage, partial loss of graft occurred in 4 cases $(13.2 \%)$ this cases healed by frequent dressing and complete loss of the graft in one case (3.3\%) regrafting was done. Post operative outcome among this group showed that complete successful in 19 cases of this group (62.7\%) with complete coverage of the defects. Flap failure occurred in 11 cases (37.3\%) in this group and this cases needed for other procedure for coverage the defect.
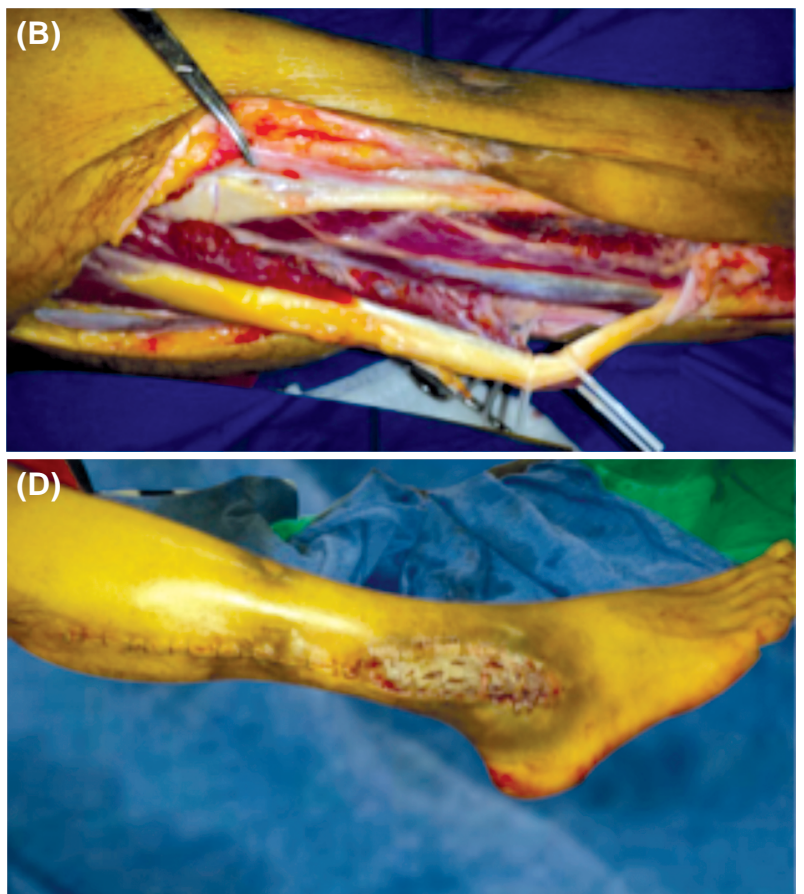

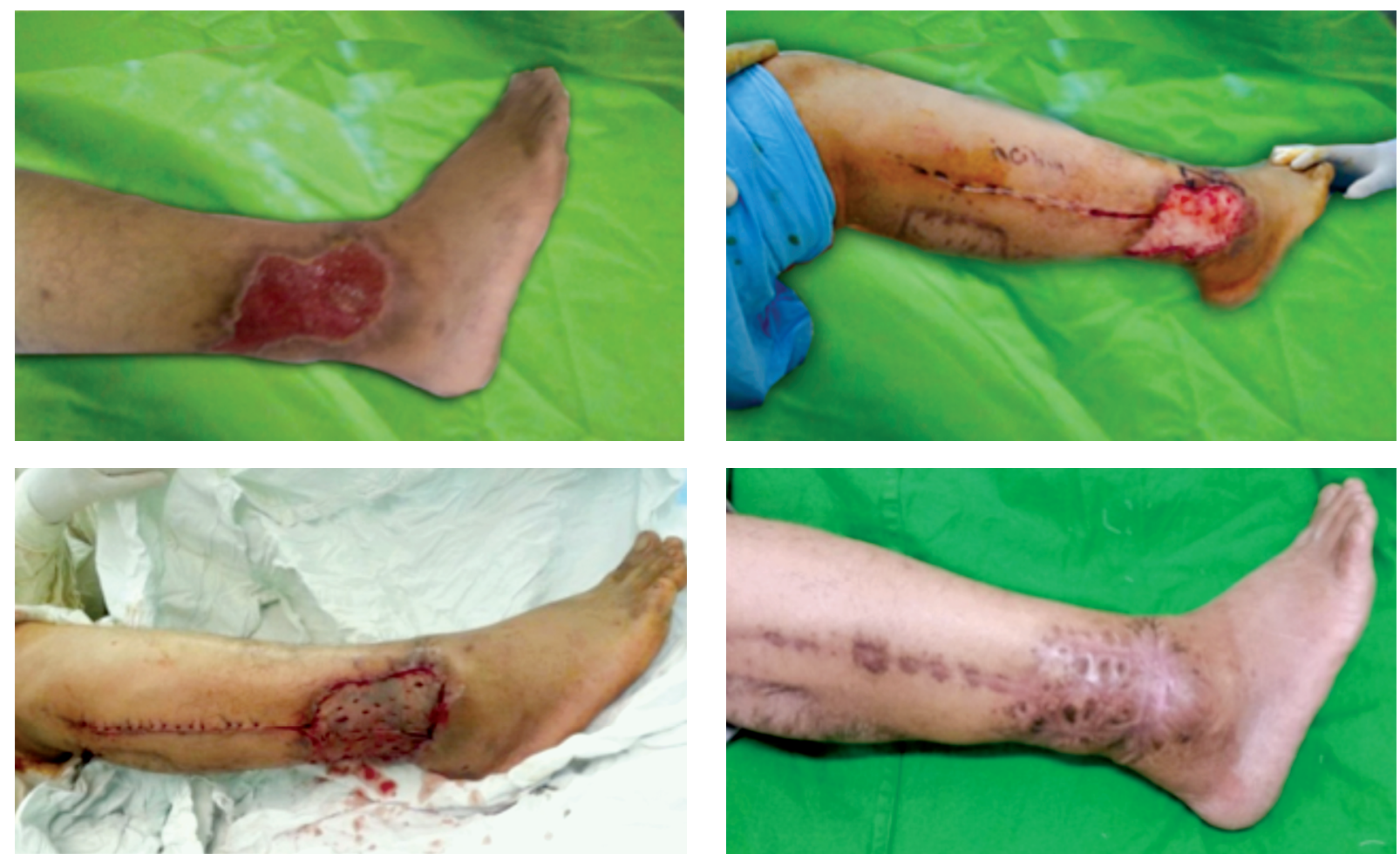

Fig. (3): Male patient 45 years old presented by post traumatic ulcer RT lateral malleolus with previous history of failed suralfasciocutenous flap covered by P.B muscle flap size of the defect $10 \mathrm{~cm}$ width $\mathrm{x} 12 \mathrm{~cm}$ length (pre \& post operative views) (splitting peroneus brevis muscle flap).
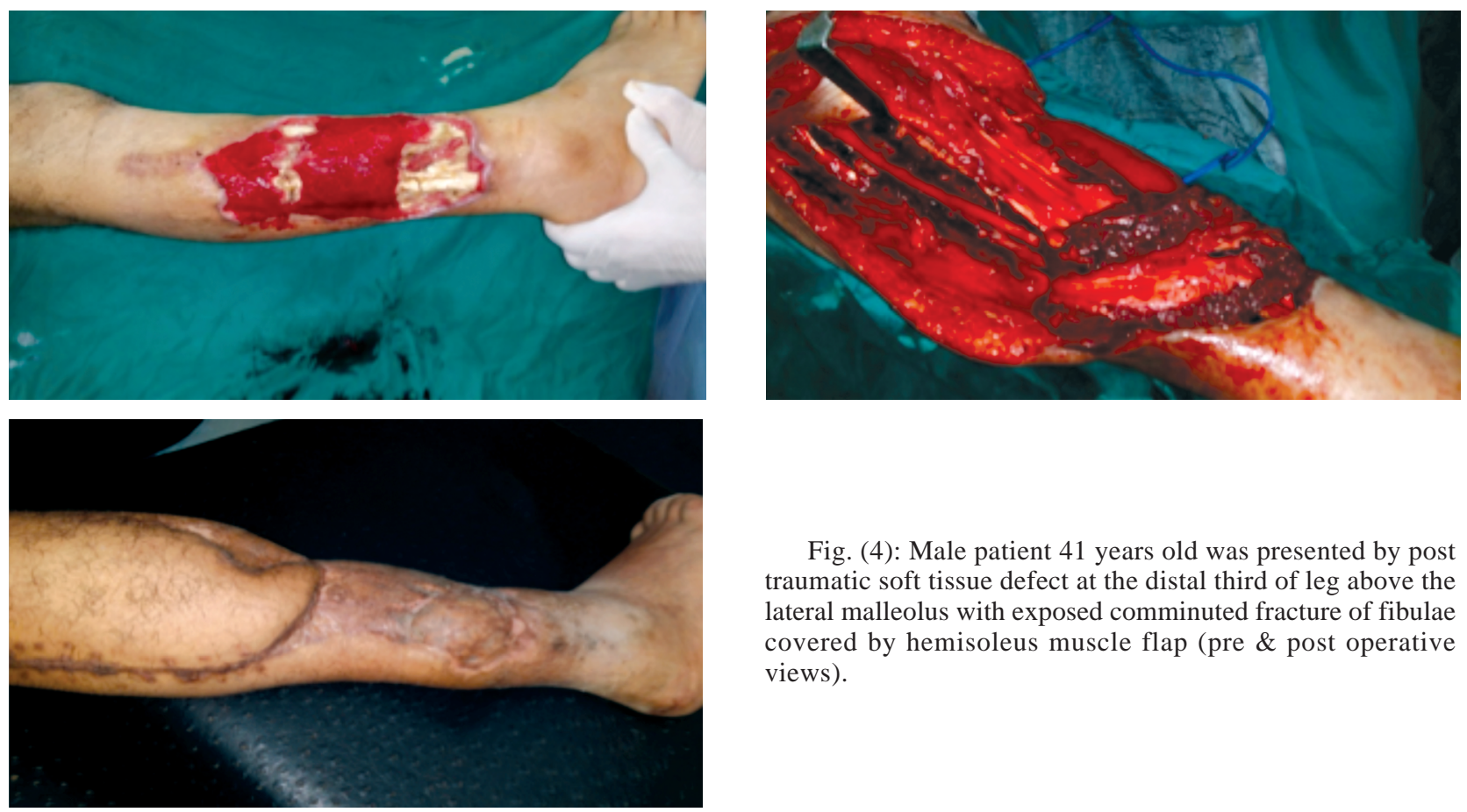

Fig. (4): Male patient 41 years old was presented by post traumatic soft tissue defect at the distal third of leg above the lateral malleolus with exposed comminuted fracture of fibulae covered by hemisoleus muscle flap (pre \& post operative views). 
Table (1): Results of group A.

\begin{tabular}{|c|c|}
\hline Characteristics & Peroneus brevisflap \\
\hline Age & Mean age in this group 41 year \\
\hline $\operatorname{Sex}$ & 29 males -1 female \\
\hline $\begin{array}{l}\text { Site of soft tissue } \\
\text { defects }\end{array}$ & $\begin{array}{l}\text { Lateral malleolus ( } 14 \text { case }) \\
\text { Medial malleolus }(2 \text { cases }) \\
\text { Exposed tendoachilies }(9 \text { cases }) \\
\text { Anterior part of ankle joint ( } 4 \text { cases }) \\
\text { Peritibial part of distal third leg ( } 1 \text { case) }\end{array}$ \\
\hline Size of the defect & $\begin{array}{l}\text { Width rang }(3 \mathrm{~cm} \text { to } 10 \mathrm{~cm}) \text { mean } 5 \mathrm{~cm} \\
\text { Length rang }(3 \mathrm{~cm} \text { to } 12 \mathrm{~cm}) \text { mean } 6.5 \mathrm{~cm}\end{array}$ \\
\hline Non splitting & 23 case \\
\hline Splitting & 7 cases \\
\hline Complications & $\begin{array}{l}\text { ( } 6 \text { cases }) \\
\text { Flap necrosis ( } 1 \text { case) } \\
\text { Partial graft loss }(4 \text { cases }) \text { healed by } \\
\text { frequent dressing } \\
\text { Graft loss ( } 1 \text { case) regrafting }\end{array}$ \\
\hline Outcome & $\begin{array}{l}\text { Successful ( } 29 \text { case) } \\
\text { Flap loss ( } 1 \text { case) need other procedure }\end{array}$ \\
\hline
\end{tabular}

Table (2): Results of group B.

\begin{tabular}{ll}
\hline Characteristics & Medial hemisoleus muscle flap \\
\hline Age & Mean age in this group 41 year \\
Sex & 28 males -2 female \\
$\begin{array}{l}\text { Site of soft tissue } \\
\text { defects }\end{array}$ & $\begin{array}{l}\text { Medial malleolus (16 case) } \\
\text { Peritibial part of distal third leg (14 case) }\end{array}$ \\
Size of the defect & $\begin{array}{l}\text { Width rang ( } 3 \mathrm{~cm} \text { to } 5 \mathrm{~cm}) \text { mean } 3.3 \mathrm{~cm} \\
\text { Length rang ( } 3 \mathrm{~cm} \text { to } 10 \mathrm{~cm}) \text { mean } 5 \mathrm{~cm}\end{array}$ \\
Complications & $\begin{array}{l}\text { (16 cases): Flap necrosis (1 case) need } \\
\text { other procedure for coverage }\end{array}$ \\
& $\begin{array}{c}\text { Distal flap necrosis }(10 \text { cases) need other } \\
\text { procedure for coverage }\end{array}$ \\
& $\begin{array}{c}\text { Partial graft loss (4 case) healed by } \\
\text { frequent dressing }\end{array}$ \\
& $\begin{array}{l}\text { Graft loss (1 case) regrafting } \\
\text { Successful (19 case), Flap failure (11 } \\
\text { case) need other procedure for } \\
\text { coverage }\end{array}$ \\
\end{tabular}

\section{DISCUSSION}

Pedicled flaps afford the surgeon a reliable and relatively straightforward reconstructive option for patients with osteomyelitis or those who may not tolerate a larger operation. The usefulness of a muscle flap to cover exposed tendon and bone is not only from its ability to physically cover the defect, but also from its ability to introduce a new vascular bed to potentiate wound healing [9].
In our study we used local muscle flaps for reconstruction of soft tissue defects at the distal third of leg.

Taylor and Pan, [9], reclassified the peroneus brevis flap as a type IV muscle flap because of the numerous vascular pedicles.

Yang, et al., [10], in cadaveric study, showed that the average length of the peroneus brevis muscle was $25 \mathrm{~cm}$. By dissecting from the uppermost point to $6 \mathrm{~cm}$ from the lateral malleolus, the muscle can be elevated as much as $19 \mathrm{~cm}$ and mobilized to cover defects distal to the lateral malleolus. However, dissection should be stopped when the muscle is sufficient to cover the defect, preserving as many of the distal pedicles as possible. By applying this principle, the reliability of the flap is greatly improved.

In our study the main distal vascular pedicle could be mapped approximately $6 \mathrm{~cm}$ proximal of the lateral malleolus. The peroneus brevis muscle flap received dual blood supply, perforators come from anterior tibial artery enter the muscle through its anterior border which not described previously and perforators from the peroneal artery enter the muscle through its posterior border.

Ensat, et al., reported that the most frequent localization of the defects was the distal fibula and lateral malleolus $(40.1 \%)$, followed by the calcaneus $(25 \%)$, the Achilles tendon (16.7\%), the anterior aspect of the tibial bone (8.9\%), the medial malleolus $(6.25 \%)$ and the lateral and dorsal aspect of the foot (3.1\%) [11]. While in our study the most frequent localization of the defect was at the lateral malleolus in 14 cases $(46.2 \%)$, medial malleolus in 2 cases $(6.6 \%)$, calcenum with exposed tendoachilles in 9 cases $(29.7 \%)$, the anterior part of the ankle in 4 cases $(13.2 \%)$ and finally at peritibial part of distal third of leg in 1 case $(3.3 \%)$. We agree with Yang, et al., in that the peroneus brevis is reliable muscle for reconstruction of most of soft tissue defect at the distal third of leg and calcaneum even at medial malleolus but don't exceed the posterior aspect of medial malleolus $[10,15,16]$.

Ensat, et al., reported that the dimensions of the defects successfully reconstructed with peroneus brevis muscle flaps ranged from $2 \times 3 \mathrm{~cm}$ to $12 \mathrm{x}$ $5 \mathrm{~cm}$, whereas the maximal flap length measured $19 \mathrm{~cm}$ [11]. While in our study the distally based peroneus brevis muscle flap used for reconstruction of defects up to $12 \mathrm{~cm}$ length $\times 10 \mathrm{~cm}$ width. splitting of the peroneus brevis muscle flap to reach double width of the flap depend on the dual blood supply 
of the muscle from peroneal and anterior tibial arteries. Splitting of the muscle belly as an open book was described by Abd-Al Moktader.

Ensat, et al., reported that Complications were classified into major complications requiring reoperations and minor complications treated conservatively. Total flap necrosis occurred in nine patients $(4.7 \%)$, Partial flap necrosis requiring reoperations occurred in (13\%). Other complications necessitating revision surgery like total or partial skin graft loss treated by regrafting, hematoma, or persisting osteomyelitis occurred in (14.5\%). Minor complications managed conservatively arose in $(9.4 \%)$. Altogether complications occurred in $41.6 \%$ of patients [11].

In our study complication were occurred in 6 cases (20\%), complete necrosis of the flap occurred in one case $(3.3 \%)$ with exposed tendoachilles which attributed to muscle flap elevation was supraperiosteal with possible injury to the blood supply of the flap. Other procedure (propeller flap) for coverage the defect was done. Partial loss of the graft occurred in 4 cases $(13.3 \%)$ complete healing only by frequent dressing and complete loss of the graft occurred in one diabetic patient (3.3\%) which necessitate regrafting.

According to donor site functional morbidity the preservation of peroneus longus muscle preserve the function of eversion of the foot. According to the esthetic appearance at the donor site only longitudinal hidden scare at the incision site through which muscle flap was harvested and no morbidity at donor site of STSG.

Previous anatomic studies of the soleus muscle demonstrate the independent neurovascular supply to either the medial or lateral belly of the muscle [12].

These important features allow a surgeon to split the muscle longitudinally along the muscle's raphe to create a muscle flap composed of only one half of the muscle or the hemisoleus. The most significant advantage of a hemisoleus muscle flap is the preservation of foot plantar flexion powered by the hemisoleus muscle belly left in situ. The medial part of the muscle is supplied throughout its length by perforators arising from the posterior tibial vessels. This constant feature makes the medial part of the muscle, the medial hemisoleus, reliable as a proximally or distally based flap [13].

While in our study using of the distally based medial hemisoleus was not a reliable flap due to flap necrosis was occurred in 11 patients $(36.3 \%)$.
Raveendran and Kumaragama, showed that the medial part of the soleus muscle reliable as a proximally or distally based flap, the average distances of the lower perforators arising from the posterior tibial artery were $6.5 \mathrm{~cm}, 11.6 \mathrm{~cm}$ and 16.8 $\mathrm{cm}$ from the medial malleolus [13].

$\mathrm{Pu}$, [14], showed that the reversed medial hemisoleus muscle flap can be used successfully for reconstruction of a sizable tibial wound in the lower third of the leg, not exceed $60 \mathrm{~cm}^{2}$. It should not be recommended to smokers unless the flap has been delayed previously. In addition, the flap should not be considered if the distal and/or middle portion of the soleus muscle has been severely traumatized by a previous injury. While in our study the size of the soft tissue defect reconstructed by medial hemisoleus muscle flap range from $3 \times 3 \mathrm{~cm}$ to $10 \times 5 \mathrm{~cm}$ (from $9 \mathrm{~cm}^{2}$ to $50 \mathrm{~cm}^{2}$ ) we didn't use the medial hemisoleus flap to reconstruct larger soft tissue defects. We used the hemisoleus muscle flap for reconstruction of soft tissue defects at the medial malleolus in (16 case 52.8\%) and peritabial part of distal third of the leg in (14 case $47.2 \%$ ). Complication was occurred in (16 case $52.8 \%$ ): Flap failure in (11 cases $36.3 \%$ ). Partial Loss of the graft occurred in (4 cases 13.2\%) and complete loss of graft in one case (3.3\%) Flap failure occurred mostly on cases with soft tissue defect at the medial malleolus (9 case) and in ( 2 case) from patients with soft tissue defects at the peritabial part of the distal third of the leg. Medial hemisoleus flap prefer to use only in reconstruction of soft tissue defects at more proximal part of the distal third of the leg to avoid the necrosis of the flap.

According to donor site morbidity the preservation of lateral belly of the muscle preserve the planter flexion of the foot. According to the esthetic appearance at the donor site only longitudinal hidden scare at the incision site through which muscle flap was harvested and no morbidity at donor site of STSG.

The esthetic outcome was accepted in most of patients in our study after reconstructed by local muscle flaps because the muscle not bulky with possibility of its atrophy which may occur later. The unbulky muscle flaps allow the patients to wear the shoes without difficulties.

\section{Conclusion:}

Local muscle flaps are reliable procedure for reconstruction of soft tissue defects at the distal third of the leg. Distally based peroneus brevis muscle flap can cover large soft tissue defects at the distal third of leg include peritabial area, anterior 
ankle, lateral malleolus, medial malleolus and calcaneum with minimal complications. Distally based medial hemisoleus muscle flap can cover small and medium size soft tissue defects in the proximal part of distal third of the leg (peritibial area and not exceed medial malleolus.

\section{Disclosure:}

The authors certify that they have no financial interest in this article. All patients consented for usage of their photos in scientific journals and clinical presentations. All persons gave their informed consent before their inclusion in the study.

\section{REFERENCES}

1- Klebuc M. and Menn Z.: Muscle flaps and their role in limb salvage. Methodist DeBakey Cardiovascular Journal, 9 (2): 95, 2013.

2- Verhelle N., Vranckx J., Van den Hof B. and Heymans O.: Bone exposure in the leg. Plastic and Reconstructive Surgery, 116 (1): 170-177, 2005.

3- Chen S.L., Chen T.M., Chou T.D., Chang S.C. and Wang H.J.: Distally based sural fasciomusculocutaneous flap for chronic calcaneal osteomyelitis in diabetic patients. Annals of Plastic Surgery, 54 (1): 44-48, 2005.

4- Erdmann D., Gottlieb N., Humphrey J.S., Le T.C., Bruno W. and Levin L.S.: Sural flap delay procedure: A preliminary report. Annals of Plastic Surgery, 54 (5): 562-565, 2005.

5- Tosun Z., Özkan A., Karaçor Z. and Savaci N.: Delaying the reverse sural flap provides predictable results for complicated wounds in diabetic foot. Annals of Plastic Surgery, 55 (2): 169-173, 2005.

6- Abd-Al Moktader M.A.: Open-book splitting of a Distally Based Peroneus Brevis Muscle Flap to Cover Large Leg and Ankle Defects. Plastic and Reconstructive Surgery, 3 (12), 2015.
7- Alain C., Masquet and Paulo S.: Soleus flap. Flap and Reconstructive Surgery, 1 (31): 423-438, 2013.

8- Attinger C.E., Ducic I., Cooper P. and Zelen C.M.: The role of intrinsic muscle flaps of the foot for bone coverage in foot and ankle defects in diabetic and non diabetic patients. Plastic and Reconstructive Surgery, 110 (4): 1047-54, 2002.

9- Taylor I.G. and Pan W.R.: Angiosomes of the leg: Anatomic study and clinical implications. Plastic and Reconstructive Surgery, 102 (3): 599-616, 1998.

10- Yang Y.L., Lin T.M., Lee S.S., Chang K.P. and Lai C.S.: The distally pedicled peroneus brevis muscle flap anatomic studies and clinical applications. The Journal of Foot and Ankle Surgery, 44 (4): 259-264, 2005.

11- Ensat F., Hladik M., Larcher L., Mattiassich G. and Wechselberger G.: The distally based peroneus brevis muscle flap-clinical series and review of the literature. Microsurgery, 34 (3): 203-208, 2014.

12- Hallock G.G.: Getting the most from the soleus muscle. Annals of Plastic Surgery, 36 (2): 139-146, 1996.

13- Raveendran S.S. and Kumaragama K.G.J.L.: Arterial supply of the soleus muscle: Anatomical study of fifty lower limbs. Clinical Anatomy, 16 (3): 248-252, 2003.

14- Pu L.L.: The reversed medial hemisoleus muscle flap and its role in reconstruction of an open tibial wound in the lower third of the leg. Annals of plastic Surgery, 56 (1): 59-64, 2006.

15- Eren S., Ghofrani A. and Reifenrath M.: The distally pedicled peroneus brevis muscle flap: A new flap for the lower leg. Plastic and Reconstructive Surgery, 107 (6): 1443-1448, 2001.

16- Bajantri B., Bharathi R., Ramkumar S., Latheef L., Dhane S. and Sabapathy S.R.: Experience with peroneus brevis muscle flaps for reconstruction of distal leg and ankle defects. Indian journal of plastic surgery: Official publication of the Association of Plastic Surgeons of India, 46 (1): 48, 2013. 